\title{
Eficiencia de los medios nutritivos basales: sólido y líquido en la etapa de establecimiento in vitro de la orquídea "Tripita" Trichopilia tortilis Lindl
}

\author{
Israel Ernesto Mendoza Abarca \\ Licenciado en biología \\ Docente investigador, Facultad Multidisciplinaria de Occidente \\ Universidad de El Salvador, El Salvador \\ israelmendoza001@hotmail.com
}

\begin{abstract}
Recepción: 22/07/2016
Aceptación: 02/08/2016

\section{Resumen}

La investigación se basó en determinar la eficiencia de los medios nutritivos basales (sólido y líquido) para el establecimiento in vitro de la orquídea "Tripita" T. tortilis Lindl., a través del número de semillas germinadas, la formación de protocormos y el desarrollo de vitro plantas.
\end{abstract}

Se utilizó un fruto inmaduro (cápsula verde), con siete meses después de la floración; desinfectada en una solución jabonosa que contenía tres gotas de Tween 20, hipoclorito de sodio al 10\% y 190ml de agua destilada. Las semillas se inocularon tomando una alícuota de $1 \mathrm{ml}$ que se depositó en cada frasco de vidrio; para ambos medios nutritivos se adicionó la misma cantidad $(1 \mathrm{ml})$ con 25 repeticiones por tratamiento. La toma de datos partió de un diseño completamente al azar, al cual se aplicó análisis de varianza.

Palabras clave: orquídeas, medios nutritivos, germinación, protocormos, imbibición, vitroplantas.

\begin{abstract}
The research was based on determining the efficiency of the basal nutrient media (solid and liquid) for the in vitro establishment of the "Tripita" orchid T. tortilis Lindl., Through the number of germinated seeds, protocormos formation and development Of vitro plants.

An immature fruit (green capsule) was used, seven months after flowering; Disinfected in a soapy solution containing three drops of Tween $20,10 \%$ sodium hypochlorite and $190 \mathrm{ml}$ of distilled water. The seeds were inoculated by taking a $1 \mathrm{ml}$ aliquot which was deposited in each glass jar; For both nutritional media the same amount $(1 \mathrm{ml})$ was added with 25 replicates per treatment. Data collection was based on a completely randomized design, to which analysis of variance was applied.
\end{abstract}

Key words: orchids, growth media, germination, protocorms, imbibition, vitro-plants. 


\section{Introducción}

La propagación natural de las orquídeas se da por vía sexual (germinación de semillas) creando asociación con micorrizas que permiten su correcta adaptación al medio. De manera artesanal, la propagación mediante esquejes provee un máximo de tres a cinco nuevas plantas al año y no permite la obtención masiva, lo que dificulta la producción de orquídeas para su conservación y/o comercialización.

Actualmente el establecimiento in vitro de orquídeas a partir de semillas verdes, al igual que otras técnicas de micropropagación, han sido trabajadas mayormente utilizando medios nutritivos de consistencia sólida, es decir con la adición de un agente gelificante (manteniendo estático el material vegetal). El medio nutritivo líquido, a pesar de sus ventajas con relación al medio sólido, ha sido poco utilizado, a pesar que dicho medio aumenta la proliferación y desarrollo vegetativo, considerándose como una alternativa para la reducción de los costos operativos en la micropropagación de orquídeas y otras especies de interés.

Los componentes de un medio nutritivo contienen nutrientes esenciales para el crecimiento y desarrollo de semillas, plántulas o cualquier tejido con que se trabaje. Surge entonces la interrogante: ¿cómo se ve afectada la eficiencia de estos nutrientes según el estado físico (sólido o líquido) del medio nutritivo?

\section{Medios nutritivos para la propagación in vitro}

Un medio de cultivo puede ser definido como "una formulación de sales inorgánicas y compuestos orgánicos requeridos para la nutrición y manipulación de los cultivos in vitro" (Roca y Mroginski, 1993). El medio nutritivo puede ser preparado con o sin la adición del agente gelificante; esto dependerá de los fines del cultivo, aunque a nivel internacional el medio nutritivo sólido ha sido más utilizado.

\section{Cultivo en medio nutritivo sólido}

Son aquellos que se les ha agregado un agente gelificante "Son ampliamente usados en el establecimiento de explantes. El explante se mantiene estático sobre el medio, con solo uno de sus extremos en contacto por donde se realiza la absorción del nutrientes" (Lorenzo et al. citado por Molina y Cabrera, 2013).

\section{Cultivo en medio líquido}

Mosqueda et al. (2010), mencionan que aunque en la fase de iniciación se utiliza preferentemente el medio sólido, el medio líquido es muy utilizado por las ventajas siguientes:

- Mejoramiento de la maduración de los embriones y como consecuencia mejoramiento de la germinación de los mismos.

- Reducción en el tiempo de germinación.

- Favorece las condiciones para la respiración y síntesis de proteínas.

- Aumento la proliferación y desarrollo vegetativo. 
McKendrick (2000), hace referencia a las semillas:

Llamadas "semillas de polvo" porque son minúsculas y contienen pocas reservas de alimento. Usualmente no germinan en el medio natural a menos que sean infectadas por un hongo micorriza, el mismo que abastece a las plantas jóvenes con azúcares y nutrientes que necesitan hasta que sean lo suficientemente grandes para fabricar su propio alimento.

Cuando la semilla germina produce una masa indiferenciada de células llamada protocormo. Manteniendo las condiciones normales, el protocormo continuará su crecimiento por varias semanas, meses o incluso años dependiendo de la especie hasta que alcance la edad apropiada para producir raíces y hojas.

En el caso de orquídeas terrestres, es de vital importancia que la relación orquídea-hongo se conserve durante los estados tempranos del ciclo de vida de la planta, ya que el protocormo enterrado no puede fabricar alimento por sí mismo. Por otro lado, los protocormos de las orquídeas epífitas son comúnmente verdes, lo que les posibilita producir parte de su alimento. La relación orquídea-hongo no ha sido en su totalidad investigada.

\section{Protocormo}

Es una masa celular característica de la familia Orquidaceae; constituyen la fase intermedia del desarrollo de una semilla y una planta totalmente formada.
Junta de Andalucía (2010), describe la formación de protocormos:

Durante la germinación, el embrión se hincha hasta alcanzar varias veces su volumen, forma una protuberancia por una hendidura de la testa y produce largos pelos protocórmicos. En esta etapa el embrión es un cuerpo con forma cónica, lustrosa y casi transparente, de 0.25$0.33 \mathrm{~mm}$ de longitud, que porta una yema en el extremo. El polo basal, es decir, la zona opuesta a la yema está cubierta en sus $2 / 3$ partes de pelos protocórmicos, que en ausencia de la radícula, tienen la misión de absorber nutrientes del medio.

Una alternativa para la conservación de orquídeas silvestres en El Salvador, es la propagación vegetativa a través del cultivo de tejidos vegetales (cultivo in vitro); que en condiciones controladas puede realizarse de manera rápida, eficiente y segura, produciendo grandes cantidades de plantas en corto tiempo.

En los últimos años, el cultivo in vitro en El Salvador ha sido considerado como una alternativa para la producción de plantas de interés comercial. Existen Instituciones como: el Centro Nacional de Tecnología Agropecuaria y Forestal "Enrique Álvarez Córdova" (CENTA), Fundación Salvadoreña para la investigación del café (PROCAFÉ), Universidad Católica de El Salvador (UNICAES), Universidad de El Salvador (UES), Escuela Nacional de Agricultura "Roberto Quiñonez" (ENA), entre otras, que se dedican a la producción 
e investigación mediante la propagación in vitro, obteniendo alta producción, pureza varietal y plantas libres de microorganismos patógenos. No obstante, dicha técnica sigue siendo poco conocida y utilizada.

\section{Importancia Ecológica}

Morales, Vanegas, Ortega, Cano, y Ramírez (2009) mencionan:

La importancia en el medio ambiente o ecosistemas para esta familia radica en la acumulación de carbono y minerales que son parte importante para la flora. También algunas orquídeas son capaces de fijar carbono en bajo niveles de luz y temperatura donde otras plantas no pueden hacerlo, además puede captar algunos nutrientes minerales en medio ambientes escasos de estos elementos.

Además, algunas orquídeas ofrecen refugio a muchos animales que viven alrededor de sus raíces; especialmente hormigas, pequeñas serpientes, ranas, pájaros etc. Las flores de algunas especies ofrecen néctar a muchas abejas, moscas, mariposas, palomillas y colibríes, a cambio del servicio de polinización que ofrecen estos organismos (p 11).

\section{Materiales y métodos}

El material vegetal se adquirió de colecciones particulares de una persona miembro de la Asociación Salvadoreña de Orquideología (ASO). Se realizó la colecta de una sola cápsula verde (aproximadamente siete meses después de la floración). Algunos autores recomiendan utilizar cápsulas verdes, debido a que el interior de la misma todo se encuentra en condición estéril; reduciendo de esta manera la proliferación de agentes patógenos (hongosbacterias) en el establecimiento del cultivo.

La figura 1 muestra cómo se realizó la colecta de Trichopilia tortilis Lindl. El uso de guantes fue necesario para evitar contacto y adición de cualquier patógeno. Con una tijera de podar desinfectada en alcohol (90\% de pureza) se realizó el corte de la cápsula, para luego limpiar el exterior de la misma con algodón y alcohol; se envolvió en papel toalla y se depositó en un recipiente hermético para su transporte. La extracción y siembra de las semillas se llevó a cabo 4 días después de la colecta. Todo esto se desarrolló en el Laboratorio de Cultivo de Tejidos Vegetales de la Escuela Nacional de Agricultura “Roberto Quiñónez” (ENA).
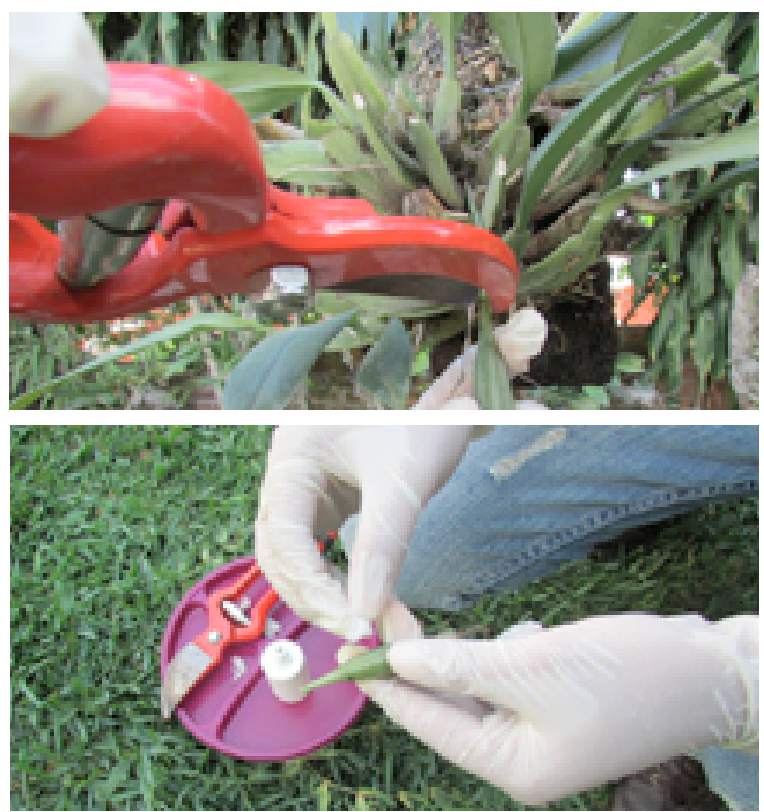

Figura 1. Recolección de la cápsula y desinfección con alcohol al 90\% de pureza. 
La composición de los medios nutritivos basales utilizados en los tratamientos, tuvieron como fundamento las sales recomendadas por Murashige y Skoog (1962). Posteriormente se ajustó el $\mathrm{pH}$ con $\mathrm{NaOH}$ $0.1 \mathrm{~N}$ a 5.65 ; por último para el medio sólido, la solución caliente $\left(98-100^{\circ} \mathrm{C}\right)$ se dispensó $30 \mathrm{ml}$ del medio en cada frasco.

De igual manera se realizó en el medio líquido, con la diferencia que a este no se le agregó agente gelificante. Por último ambos medios se esterilizaron a $121^{\circ} \mathrm{C}$ (15 minutos) a 20 libras de presión.

En la asepsia superficial, la cápsula se lavó con agua corriente y jabón líquido antibacterial, se mantuvo en agitación constante por cinco minutos en un solución jabonosa que contenía tres gotas de Tween 20 (detergente y emulsionante); $10 \%$ de hipoclorito de sodio y 190ml de agua destilada. Pasado este tiempo, la cápsula sumergida en la solución jabonosa se trasladó a la cámara de flujo laminar para la extracción de las semillas.

Sosteniendo la cápsula con una pinza se realizó un corte longitudinal, utilizando un bisturí, tomándose cada mitad de la cápsula con las pinzas, para luego hacer un raspado de semillas (Ver figura 2, 3 y 4), depositándolas en un beaker que contenía $30 \mathrm{ml}$ de agua estéril. Del beaker, con una jeringa descartable, se tomó una alícuota de $1 \mathrm{ml}$ que se depositó en Tratamieno 1 (medio líquido- 25 repeticiones) y en Tratamiento 2 (medio sólido- 25 repeticiones).



Figura 2. Proceso de desinfección y siembra de cápsula.

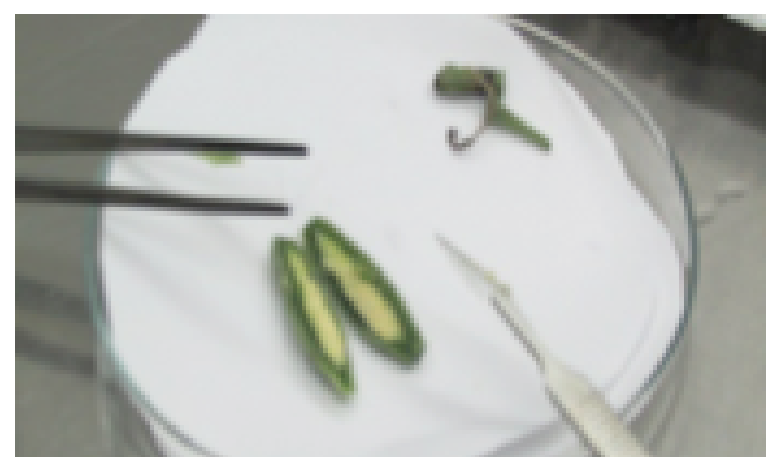

Figura 3. Lavado en solución jabonosa.

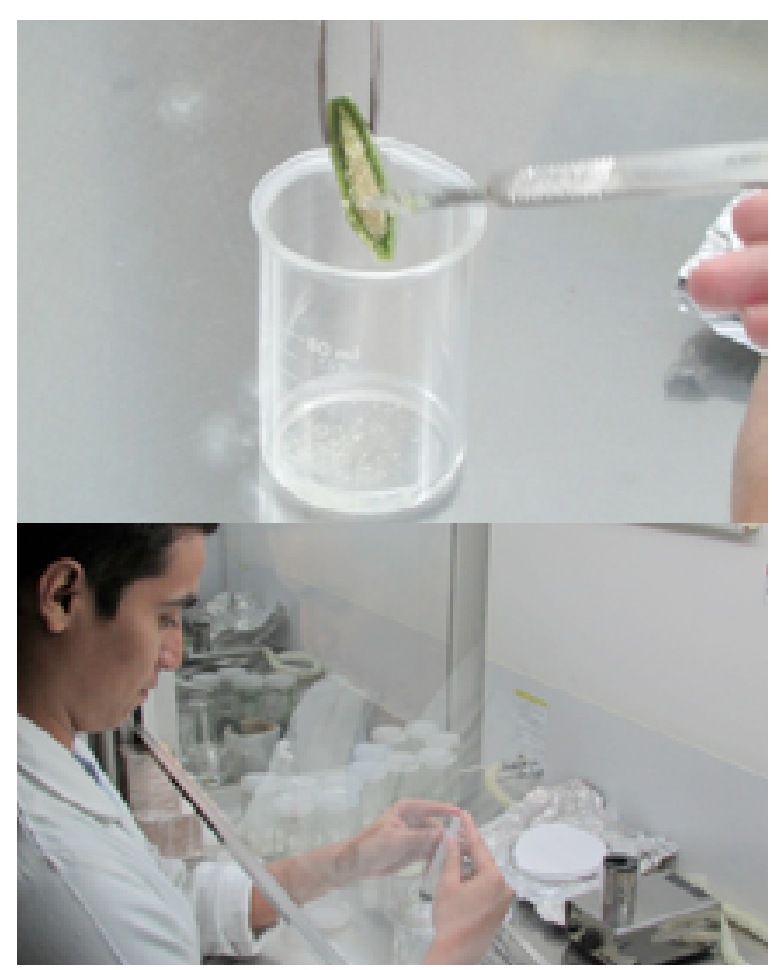

Figura 4. Disección de la cápsula para extraer las semillas. 


\section{Traslado al área de incubación}

Condiciones físicas del área de incubación:

- Fotoperiodo de 16 horas luz /

8 horas oscuridad.

- Temperatura $24-25^{\circ} \mathrm{C}$.

- Humedad relativa entre $28-30 \%$.

- Intensidad lumínica de 2000-3000lux (Lumen $/ \mathrm{m}^{2}$ ).

Los primeros 12 días de sembradas las semillas en los tratamientos, se mantuvieron en luz indirecta. Luego los frascos (medio sólido) pasaron a estantes donde se tenía influencia de luz directa. Los frascos con medio líquido se colocaron en el agitador de matraces a 150 revoluciones por minuto, manteniendo las semillas en agitación constante durante toda la fase experimental.

Durante cinco meses se realizaron 10 muestreos cada 15 días, evaluando las 25 repeticiones para cada tratamiento, observando el desarrollo fenológico de las semillas a través del estereomicroscopio. Desde el momento de la siembra se tomaron en cuenta los siguientes cambios físicos: coloración (blanco, amarillo, y verde), imbibición (hidratación $\mathrm{u}$ aumento de volumen de las semillas), ruptura de la testa seminal, formación de protocormos, surgimiento de primordios foliares y radiculares, así como desarrollo de vitroplantas.

La evaluación de ANOVA se realizó utilizando el paquete estadístico MSTAT-C, a través de un diseño completamente al azar, para determinar la existencia de diferencias significativas al $(\mathrm{p} \leq 0.05)$ y $(\mathrm{p} \leq$ 0.01 ) entre los tratamientos en la etapa de establecimiento in vitro. Estadísticamente el ANOVA determinó cuál medio nutritivo es superior al otro.

\section{Resultados y discusión}

El tiempo de evaluación fue de 120 días a partir de la siembra. Al tercer día, en ambos tratamientos (T1 y T2) se observó un cambio en la coloración de las muestras, inicialmente blancas tornándose amarillasverde claro.

Tal como lo muestra la figura 5, luego de 20 días se contabilizaron 225 semillas germinadas en T1, y 307 en el T2.

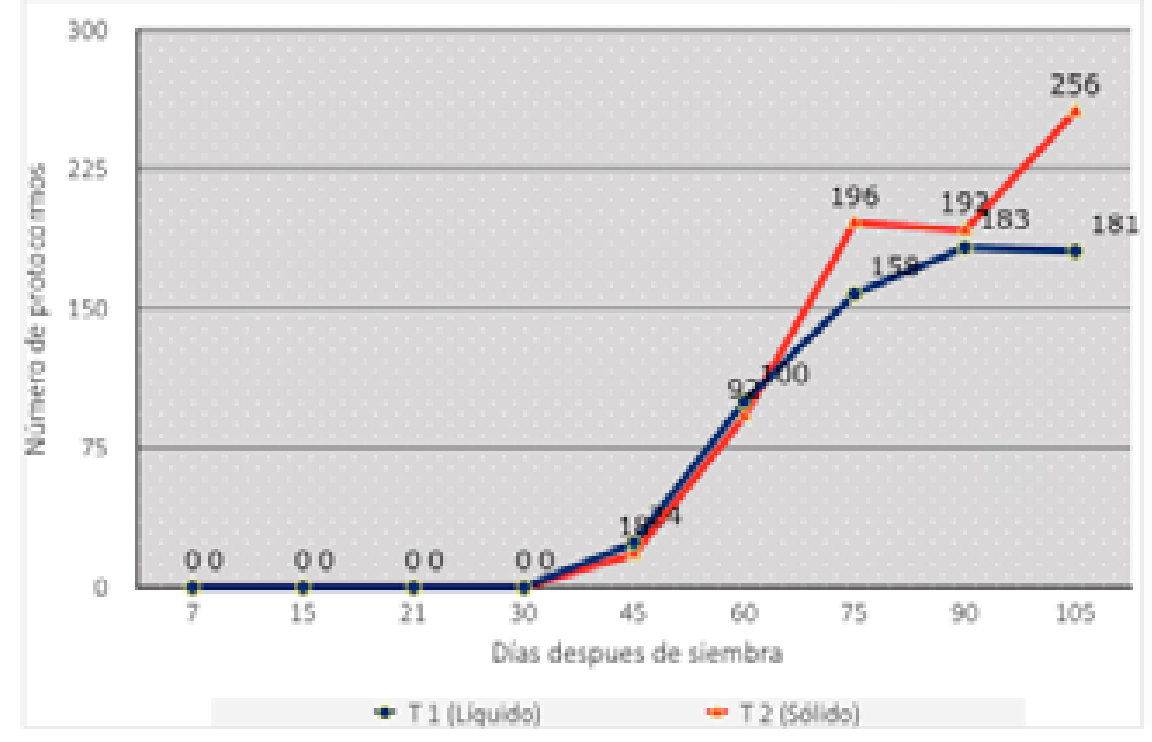

Figura 5. Número de semillas germinadas. Visualización de primeros muestreos con alto nivel germinativo y una reducción considerable en los últimos muestreos. 


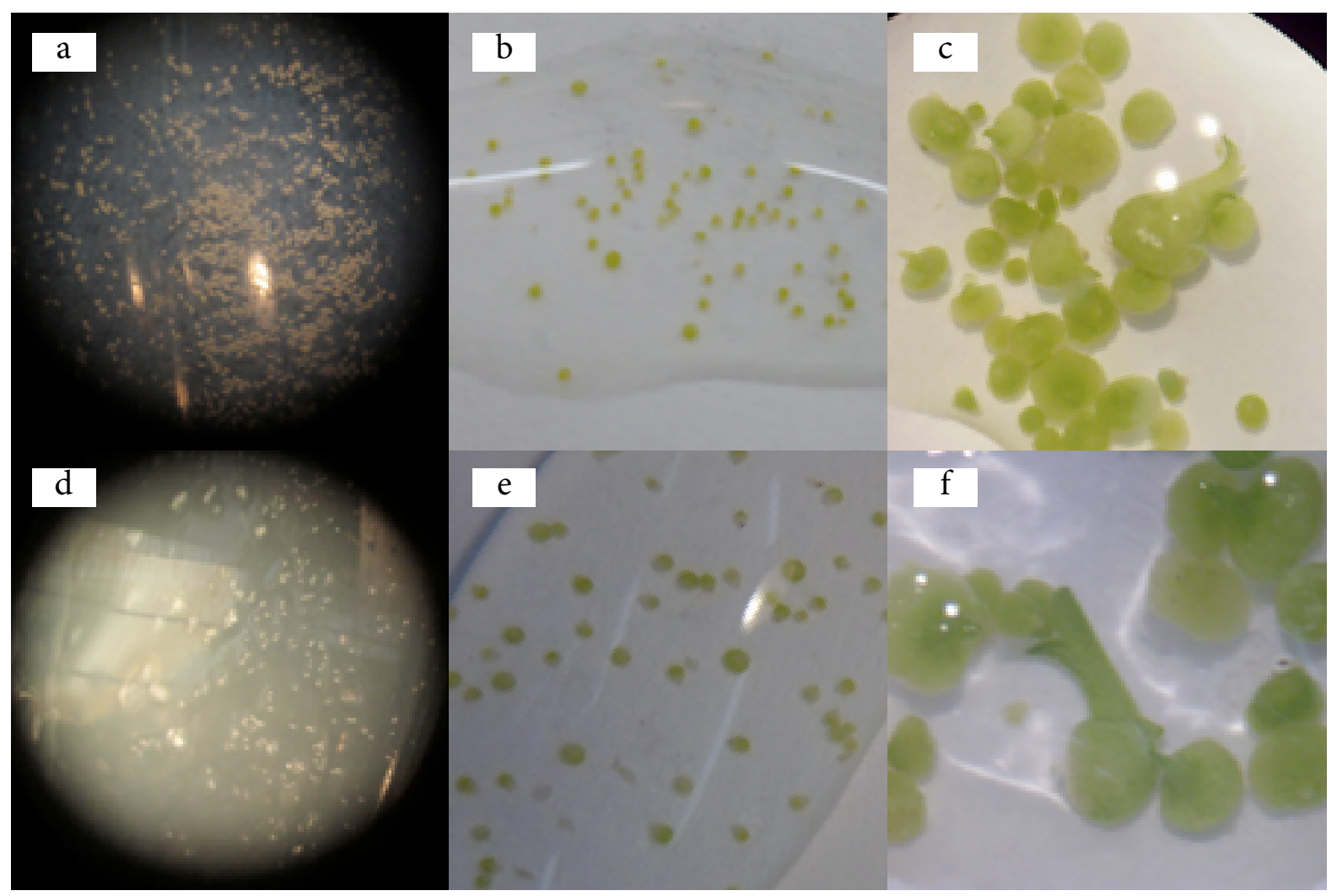

Figura 6. Desarrollo germinativo de semillas. En las imágenes a, b y c se observan las semillas en medio líquido; mientras que en las imágenes $\mathrm{d}$, e y f se evidencian las semillas en medio sólido. En las imágenes a y d las semillas tenían tres días en estado de imbibición. Por otro lado, en las imágenes b y e, con 45 días, se observa poca presencia de semillas en imbibición. A los 90 días (fotografías c y f), el mayor número son protocormos e inicia la presencia de primordios foliares.

La sumatoria total de semillas en 120 días de evaluación resultó para T1 con 1120 semillas germinadas y 1221 en T2; de manera general, los números en la germinación de semillas fueron muy similares en los tratamientos. De igual manera Escobar et al. (2008) trabajaron con la especie Oncidium stramineun Lindl, iniciando la germinación a los cuatro días de sembradas las semillas, presentando un hinchamiento pronunciado y una coloración verde pálido del embrión. No así para Muñoz (2011), quien esperó 130 días para la germinación de Cyrtochilum macranthum utilizando MS + carbón activado + pulpa de plátano.
En estudios realizados por Ávila et al. (2006), se encontró que el medio MS (1962) completo sin reguladores de crecimiento es un medio óptimo para que se produzca la germinación de semillas, entre los 30 y los 45 días después de la siembra, tal como se observó en este trabajo. Sin embargo, estos autores reportan igualmente que el tiempo y la germinación tiene relación directa con la especie o variedad de orquídea con la que se trabaje.

Como se demuestra en el ANOVA, el desarrollo germinativo para $\mathrm{T} 1$ y T2 resultó con diferencia significativa $(\mathrm{p} \leq 0.05)$ en el muestreo 1 y diferencias altamente 
significativas ( $\mathrm{p} \leq 0.01)$ en los muestreos 8 y 9 . Posiblemente esto se debe a que no todas las semillas iniciaron el proceso de imbibición de manera simultánea.

Según lo anterior, a los 120 días T1 y T2 mostraron datos estadísticos muy similares. Esto es contrario para algunos autores, debido a que el medio nutritivo en estado líquido debería brindar mayores beneficios en la propagación in vitro de orquídeas, acortando los tiempo para la germinación y aumentando el desarrollo vegetativo.

Por otra parte Rodríguez et al. (2003), mencionan que en la germinación asimbiótica in vitro de semillas de Cattleya labiata; "El efecto positivo del medio de cultivo líquido en la germinación de las semillas puede estar dado, entre otros factores, por la mejor aireación, el incremento de la superficie aérea y la dilución de inhibidores".

\section{Formación de protocormos}

La formación de protocormos se comenzó a evidenciar a los 45 días (figura 7); en T1 hubo 18 protocormos, mientras que en T2 se obtuvo 24. A los 75 días, habían 158 en T1; mientras que para T2 se tuvo 196. En T2 se observó que algunos protocormos mostraban surgimiento y elongación de la primera hoja; no así en T1 donde este proceso se inició a los 90 días. El mayor número de protocormos para $\mathrm{T} 2$ se obtuvo a los 105 días con 256, mientras que para T1 la cantidad fue de 181 protocormos.

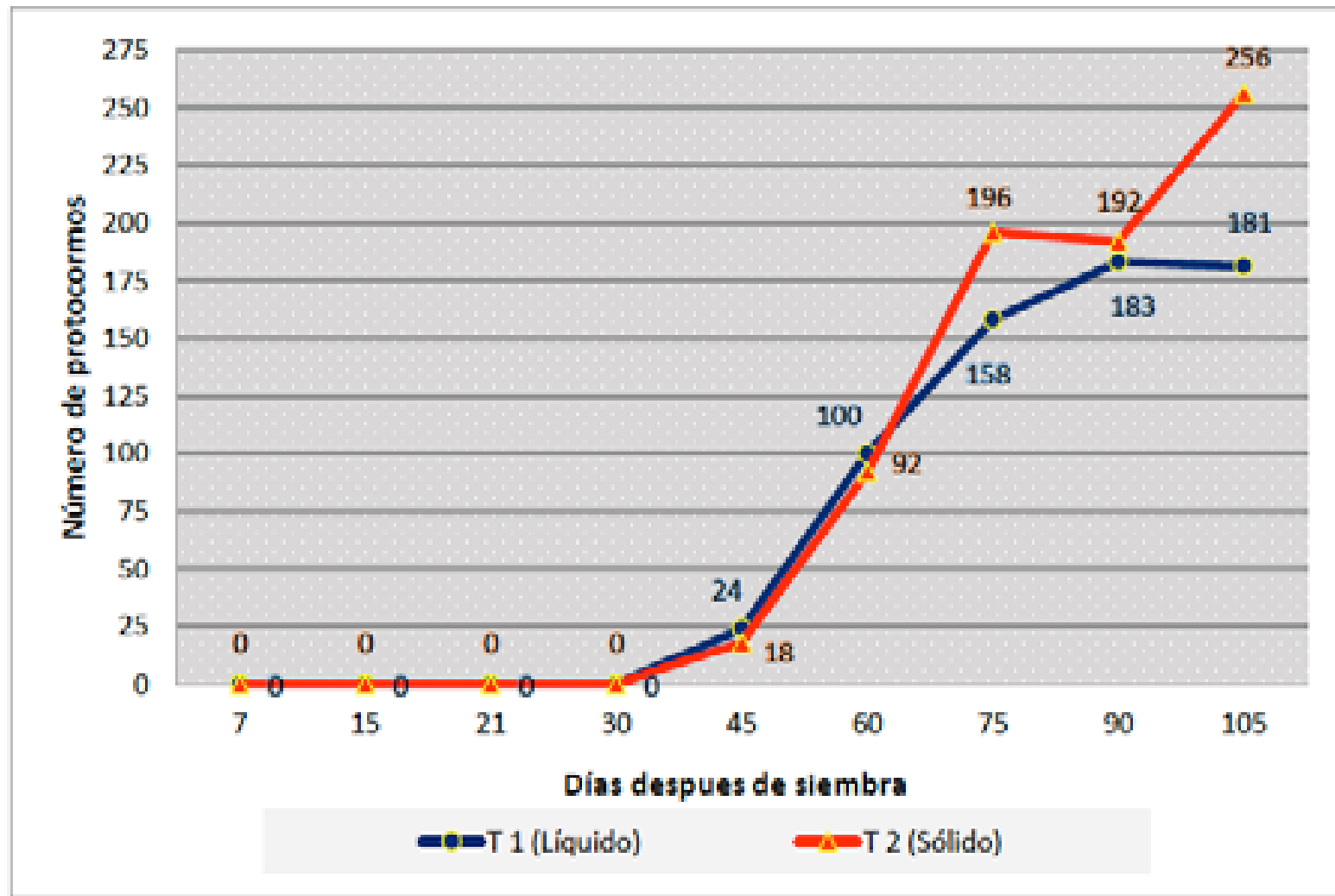

Figura 7. Desarrollo de protocormos de manera relativamente homogénea. La disminución en el número de protocormos a los 120 días, evidencia que los mismo han comenzado la emergencia de primordios foliares y radiculares. 




Figura 8. Desarrollo de protocormos después de 45 de iniciada la etapa de establecimiento.

En las imágenes a y b, se observan las semillas con 90 días, en sus respectivos tratamientos. En la imagen c, las semillas a los 75 días, en donde el protocormo se encuentra totalmente definido con presencia de rizoides (visto a 100x). En las fotografías d, e y f se observan los protocormos formados. En esta fase se inició una disminución considerable de protocormos, emergencia y elongación de hojas. A los 120 días (fotografías g y h) se observa la aparición de hojas desarrolladas y raíces, número muy reducido de semillas en imbibición y protocormos. Finalmente, (fotografías i, j, k, ly m) desarrollo desde imbibición, protocormos, emergencia y desarrollo de hoja. 
De manera general, la sumatoria de protocormos formados en todos los muestreos para T1 resultó de 724 y para T2 de 852 . Por tanto numéricamente se encontró una diferencia de 128 protocormos en los tratamientos. De acuerdo a Pineda (2008), quien trabajó en la multiplicación in vitro de la orquídea Ckuitlauzina pendula Lex, logró la formación de cuerpos protocórmicos a los 60 días, utilizando medio basado en las sales de Murashige y Skoog, sin reguladores de crecimiento.

Estadísticamente para la formación de protocormos no se encontraron diferencias en los tratamientos, brindando números aceptables para la variable en cuestión (ver tabla 2. a 2.5). La razón de esta similitud podría deberse a que todas las semillas de T. tortilis Lindl tienen la misma capacidad de absorber nutrientes no importando el estado físico del medio nutritivo.

\section{Porcentaje de germinación}

A los 120 días, el ANOVA demostró en los tratamientos diferencias altamente significativas al $\mathrm{p} \leq 0.01$; el valor del coeficiente de variación se encontró de $4.83 \%$, brindando certeza y credibilidad al ANOVA. Según lo anterior, T2 fue más eficiente en la germinación de semillas de T. Tortilis Lindl con un $91.641 \%$, contrario a T1 con un $78.944 \%$.
Se han obtenido resultados aceptables para la germinación de T. tortilis Lindl, contrario a lo que menciona Mosqueda et al. (2010), las semillas sembradas a partir de cápsulas que no han madurado lo suficiente podrían germinar lentamente o simplemente no germinar. Estos autores obtuvieron promedios de germinación de semillas maduras en 70 a $90 \%$, empleando los medios VW (Vacin y Went, 1949), MS (Murashigue y Skoog, 1962), y MS a la mitad de su concentración, adicionando $0.1 \%$ de carbón activado a todos los medios.

\section{Desarrollo de vitroplantas}

La tabla 1 muestra que a partir del muestreo 7 , en T2 se comenzó a observar que algunos protocormos mostraban la emergencia de primordios foliares (figura 9). Ambos tratamientos, a los 90 días, presentaban completo desarrollo del área foliar (figura 9b), encontrándose para T1 la cantidad de 24 vitroplantas y para T2 una muestra de 27. Posteriormente, en el muestreo 9 (105 días), los protocormos en $\mathrm{T} 1$ habían alcanzado mayor desarrollo que en T2, con 240 vitroplantas y 72 respectivamente (figura 9 ).

Al término de la fase experimental, se logró observar en ambos tratamientos gran cantidad de vitroplantas, totalmente desarrolladas con presencia de hojas y raíces (ver figura 9 c y d). 
Tabla 1. Número de semillas desarrolladas (vitoplantas)

\begin{tabular}{|c|c|c|c|c|c|c|c|c|c|c|}
\hline \multirow{2}{*}{ Tratamiento } & \multicolumn{10}{|c|}{ Muestreos } \\
\cline { 2 - 12 } & $\mathbf{1}$ & $\mathbf{2}$ & $\mathbf{3}$ & $\mathbf{4}$ & $\mathbf{5}$ & $\mathbf{6}$ & $\mathbf{7}$ & $\mathbf{8}$ & $\mathbf{9}+$ & $\mathbf{1 0}$ \\
\hline T1 (Líquido) & 0 & 0 & 0 & 0 & 0 & 0 & 0 & 24 & 240 & 154 \\
\hline T2 (Sólido) & 0 & 0 & 0 & 0 & 0 & 0 & 3 & 27 & 72 & 283 \\
\hline
\end{tabular}

Nota: $+=$ Contaminación de repetición.

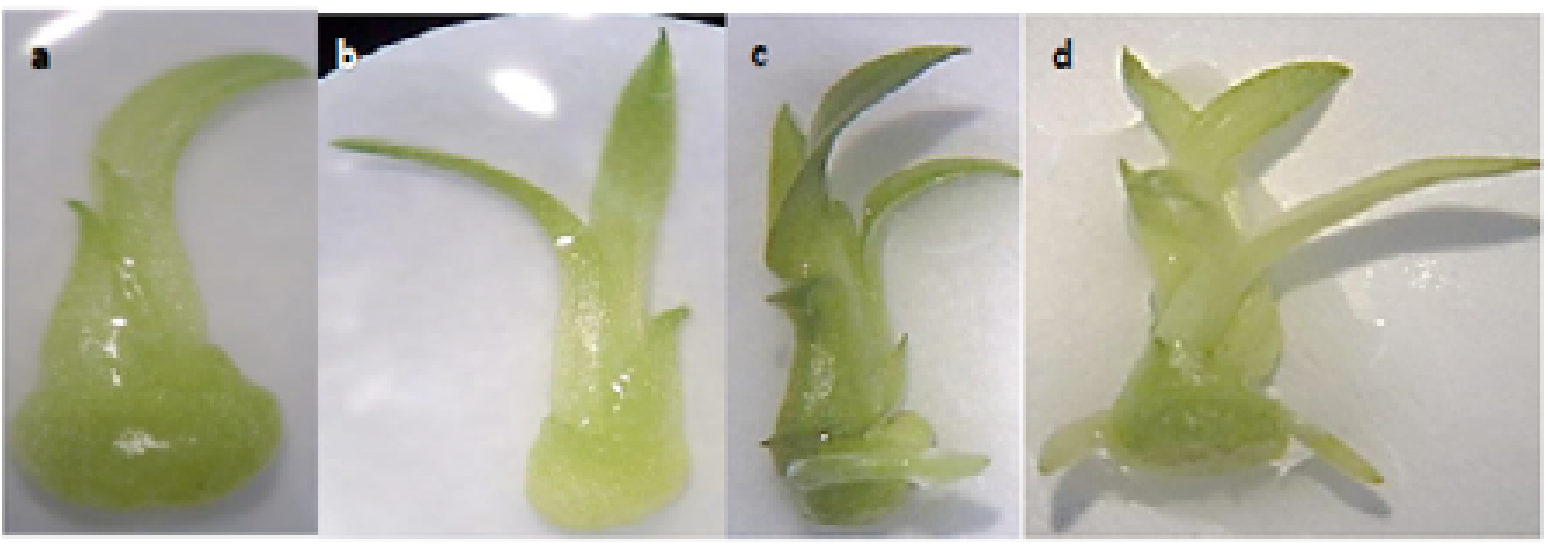

Figura 9. Formación de vitroplantas a partir de protocormos. A los 75 días (imagen a) se observan protocormos con emergencia de hoja. En la imagen b, a los 90 días se visualiza el desarrollo de primeras hojas. A los 120 días (imágenes c y d) son evidentes hojas completamente desarrolladas con presencia de raíces.

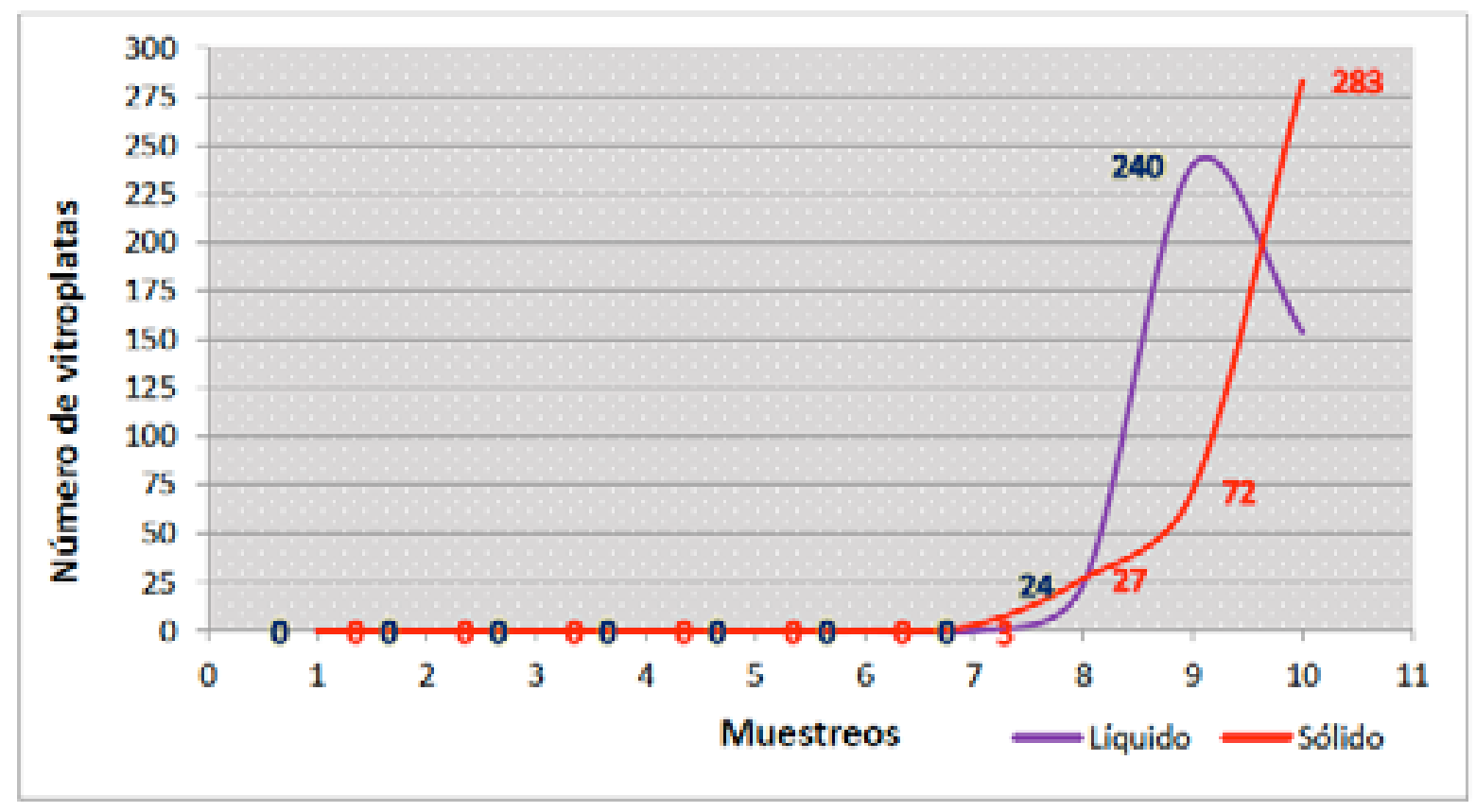

Figura 10. Gráfica de desarrollo de vitroplantas en 120 días de muestreos. 
El número total de vitroplantas para ambos tratamientos demostró una leve mayoría en T1 con 418 semillas, con respecto a 385 semillas en T2. A los 120 días aún se observaron semillas en imbibición y formación de protocormos, esto posiblemente debido a que no todas las semillas reaccionaron a los tratamientos al mismo tiempo.

Cumplidos los 120 días de evaluación, se contabilizaron las semillas que se encontraban en sus diferentes estadios de desarrollo, con la finalidad de conocer la cantidad que se habían sembrado en cada tratamiento; además observar la viabilidad y respuesta a cada uno de ellos. La tabla 2 muestra los resultados finales para el T1 (aproximado de 7 146) entre semillas en imbibición, protocormos, vitroplantas, de las cuales 625 resultaron semillas no viables y muertas. Brevedan et al. (2010), consideran que semilla viable es aquella que tiene su embrión sano y potencial capacidad germinativa.

Además, en tres repeticiones se encontró presencia de contaminación (hongo-bacteria), descartándose inmediatamente del ensayo. Como dato final, 6521 semillas continuarán el proceso de micropropagación, luego de haber salido de la etapa evaluada (establecimiento).

Tabla 2. Conteo final de repeticiones del T1 (medio líquido)

\begin{tabular}{|c|c|c|c|c|c|}
\hline Repeticiones & Imbibición & Protocormos & Vitro plantas & $\begin{array}{c}\text { Semillas } \\
\text { muertas }\end{array}$ & $\begin{array}{c}\text { Semillas no } \\
\text { germinadas }\end{array}$ \\
\hline 1 & 89 & 377 & 411 & 55 & 29 \\
\hline 2 & 33 & 131 & 455 & 23 & 17 \\
\hline 3 & 52 & 321 & 429 & 33 & 23 \\
\hline 4 & 180 & 338 & 47 & 63 & 17 \\
\hline 5 & 133 & 245 & 369 & 38 & 21 \\
\hline 6 & 21 & 61 & 122 & 12 & 17 \\
\hline 7 & 62 & 315 & 137 & 43 & 63 \\
\hline 8 & 14 & 445 & 111 & 9 & 12 \\
\hline 9 & 180 & 338 & 47 & 63 & 17 \\
\hline 10 & 95 & 382 & 15 & 7 & 16 \\
\hline 11 & 11 & 78 & 22 & 9 & 3 \\
\hline 12 & 13 & 85 & 354 & 29 & 6 \\
\hline Sub totales & 883 & 3116 & 2519 & 384 & 241 \\
\hline TOTAL & 7146 & & & & \\
\hline
\end{tabular}

Nota: Los números totales reflejan la cantidad de semillas encontradas en cada repetición después de los 10 muestreos (120 días). 
Los resultados finales para el medio sólido (tabla 3) mostraron un aproximado de 8266 entre semillas en imbibición, protocormos y vitroplantas, de las cuales 864 resultaron semillas no viables y muertas. Además, en cuatro repeticiones se encontró presencia de contaminación (hongo-bacteria), descartándose inmediatamente del ensayo. Obteniéndose un número final de 7402.

Tabla 3. Conteo final de repeticiones del T2 (medio sólido)

\begin{tabular}{|c|c|c|c|c|c|}
\hline Repeticiones & Imbibición & Protocormos & Vitro plantas & $\begin{array}{c}\text { Semillas } \\
\text { muertas }\end{array}$ & $\begin{array}{c}\text { Semillas no } \\
\text { germinadas }\end{array}$ \\
\hline 1 & 45 & 128 & 310 & 62 & 17 \\
\hline 2 & 127 & 267 & 463 & 74 & 66 \\
\hline 3 & 23 & 128 & 118 & 13 & 7 \\
\hline 4 & 202 & 649 & 132 & 39 & 27 \\
\hline 5 & 79 & 194 & 55 & 15 & 79 \\
\hline 6 & 62 & 101 & 9 & 53 & 43 \\
\hline 7 & 31 & 311 & 172 & 16 & 77 \\
\hline 8 & 46 & 147 & 289 & 22 & 56 \\
\hline 9 & 21 & 65 & 133 & 19 & 43 \\
\hline 10 & 19 & 107 & 228 & 65 & 23 \\
\hline 11 & 86 & 55 & 112 & 31 & 17 \\
\hline Sub totales & 741 & 2152 & 2021 & 409 & 455 \\
\hline TOTAL & $\mathbf{5 7 7 8}$ & \multicolumn{5}{l}{} \\
\hline
\end{tabular}

Nota: Los números totales reflejan la cantidad de semillas encontradas en cada repetición después de los 10 muestreos (120 días).

\section{Conclusiones}

La germinación de la orquídea T. tortilis Lindl se efectuó con éxito en ambos tratamientos, utilizando las sales de Murashige y Skoog, permitiendo el desarrollo óptimo del embrión y de las diferentes fases de crecimiento.

Estadísticamente para la formación de protocormos no se encontraron diferencias en los tratamientos, brindando números aceptables para la variable en cuestión (ver tabla 2. a 2.5). La razón de esta similitud podría deberse a que todas las semillas de T. tortilis Lindl tenían la misma capacidad de absorber nutrientes no importando el estado físico del medio nutritivo. La sumatoria de protocormos formados en todos los muestreos para T1 resultó de 724 y para T2 de 852 .

Después de 120 días, en términos generales, la eficiencia de los medios nutritivos en la etapa de establecimiento in vitro, basándonos en los datos estadísticos fue muy similar. $\mathrm{Nu}$ méricamente (Tabla 2 y 3 ), el medio nutritivo 
líquido fue superior al medio nutritivo sólido con 7146 y 5778 individuos en sus diferentes estadios de desarrollo. Los niveles de contaminación (hongo-bacteria) en ambos tratamientos fueron bajos, posiblemente a la cuidadosa desinfección superficial de la cápsula $y$ del instrumental utilizado en toda la etapa de establecimiento.
Dada la limitada propagación de orquídeas por la vía sexual (germinación de semillas) y de forma artesanal; la utilización de las sales de Murashige y Skoog, independientemente del estado físico en que estas se encuentren, son una alternativa viable para la propagación masiva de orquídeas, ya sea con fines de conservación y/o comercialización.

\section{Referencias}

Ávila, I. y Salgado, R. (2006). Propagación y mantenimiento in vitro de orquídeas Mexicanas, para colaborar en su conservación. Biológicas. Vol. 8.

Castañeda, Z.M. (2008). Propagación y conservación del lirio de todos los santos Laelia anceps Lindl. Subsp. Anceps f. semialba (Orquidaceae) a través del cultivo de tejidos. (Tesis inédita de Licenciatura en Biología) Universidad Veracruzana, México.

El Salvador, Ministerio de Medio Ambiente y Recursos Naturales (2013). Dirección General del Observatorio Ambiental, Gerencia de Meteorología. Anuario Climatológico San Andrés. La Libertad, El Salvador.

Escobar, F.G., Solano, J.P., Vásquez, G. y Colinas, M.T. (2008). Propagación in vitro de Oncidium stramineum Lindl. Chapingo, México.

España, Junta de Andalucía. (2010). Patrimonio natural y gestión de espacio protegidos. orquideas.pdf. Recuperado de http://www.juntadeandalucia.es/medioam

McKendrick, S. (2000). Manual para la Germinación in vitro de Orquídeas. Colombia: Ceiba Foundation for Tropical Conservation.

Mosqueda, A.M., Camero, J.G., Lázaro, E.C. y Hernández, A.F. (2010). Germinación in vitro de Semillas y Desarrollo de Plántulas de Orquídeas Silvestres de Tabasco. Universidad Juárez Autónoma de Tabasco, México. 
Muñoz, M.I. (2011). Evaluación de medios de cultivo para la germinación “in vitro” de las orquídeas cyrtochilum macranthum y epidendrum jameisonic rchb.f. (Tesis inédita de ingeniería agronómica). Universidad Técnica de Ambato Facultad de Ingeniería Agronómica, Ecuador.

Murashige, T. y Skoog, F. (1962). A revised medium for rapid growth and bioassay with tobacco tissue cultures. Physiol, Plant. V. 15, p. 437-97.

Pineda, U. (2008). Multiplicación in vitro de la orquídea Cuitlauzina pendula Lex. (Tesis inédita de ingeniería agronómica). Universidad Michoacana de San Nicolás de Hidalgo. México. Recuperado de http://bibliotecavirtual.dgb. umich.mx:8083/jspui/bitstream/123456789/5533/1/M.pdf

Roca, W. y Mroginski, L. A. (1993). Cultivo de tejidos en la agricultura. Fundamentos y Aplicaciones. Centro Internacional de Agricultura Tropical CIAT. Cali.

Rodríguez, L., González, R., Díaz, A., Fajardo, E., Sánchez, E. y Hernández, J. (...) González, J. (2003). Influencia de diferentes factores en la germinación asimbiótica in vitro de semillas de Cattleya labiata. Biotecnología vegetal. Vol. 3. Centro de Desarrollo de la Montaña Limonar de Monte Ruz, El Salvador, Guantánamo, Cuba.

Salazar, S.A. y Cadavid, I.C. (2008). Micropropagación de Cattleya quadricolor. (Tesis inédita de ingeniería agronómica). Universidad Eafit, Medellín, Colombia. 